\title{
Letter to Sullivan BJ et al. "Diaphragmatic Peritoneal Stripping Versus Full-Thickness Resection in CRS/HIPEC: Is There a Difference?"
}

\author{
Fabio Carboni, MD, PhD, and Mario Valle, MD, FACS \\ Department of Digestive Surgery, IRCCS Regina Elena National Cancer Institute, Rome, Italy
}

Dear Editor,

We read with great interest the article by Sullivan et al. ${ }^{1}$ on their results following different types of diaphragmatic surgery in cytoreductive surgery (CRS)/hyperthermic intraperitoneal chemotherapy (HIPEC) for peritoneal carcinomatosis of various origin. We recently updated our experience, and the study will soon be published. Surgical management of the diaphragmatic surface is often required for complete cytoreduction, constituting a subject of great topicality and interest, although available studies in literature are limited. As clearly confirmed by the authors, diaphragmatic procedures significantly increase the rate of postoperative overall morbidity and especially respiratory complications. ${ }^{2}$ We must compliment them for their outstanding experience in this field. The paper is well written, and the message is extremely clear and relevant.

Having said that, we wish to pose a couple of questions concerning the methodology. No statistical difference in the incidence of pleural effusion with or without chest tube placement was reported (Table 5). However, in the latter subgroup, half of the patients had this complication. It would be interesting to know the definition of asymptomatic and symptomatic effusions and when tube removal occurred for a better understanding of these results. In our experience, we had an extremely low incidence rate due to the routine chest tube placement after diaphragmatic procedures. We completely agree with the authors that a randomized clinical trial would be required to determine the answer.

\footnotetext{
(C) Society of Surgical Oncology 2019
}

First Received: 13 September 2019;

Published Online: 18 October 2019

F. Carboni, MD, $\mathrm{PhD}$

e-mail: fabiocarb@tiscali.it
The second question is simply related to the unreported incidence of pneumothorax in the study (Table 3). Since this is another well-recognized complication after diaphragmatic surgery, ${ }^{3}$ we were positively surprised by this zero incidence. In our experience, we had a negligible incidence rate of pneumothorax, which we attribute to both the meticolous surgical technique and the routine chest tube placement. To what do you attribute your impressive results?

We again congratulate the authors on their extremely interesting paper focusing on such a complex issue and are grateful for the opportunity to discuss it.

DISCLOSURE None.

\section{REFERENCES}

1. Sullivan BJ, Bekhor EY, Carpiniello M, et al. Diaphragmatic peritoneal stripping versus full-thickness resection in CRS/HIPEC: is there a difference? Ann Surg Oncol 2019 Sep 9. https://doi.org/ 10.1245/s10434-019-07797-8. (Epub ahead of print).

2. Cascales Campos $P$, Martinez Insfran LA, Wallace $D$, et al. Identifying the incidence of respiratory complications following diaphragmatic cytoreduction and hyperthermic intraoperative intraperitoneal chemotherapy. Clin Transl Oncol. 2019 Aug 7. h ttps://doi.org/10.1007/s12094-019-02195-8. (Epub ahead of print).

3. Singh B, Singh G, Alzahrani N, Arrowaili A, Morris DL. Long term survival and perioperative propensity score matched outcomes in diaphragmatic interventions in cytoreductive surgery + intra-peritoneal chemotherapy. Eur J Surg Oncol. 2019;45:620-4.

Publisher's Note Springer Nature remains neutral with regard to jurisdictional claims in published maps and institutional affiliations. 